\title{
Mortality among contraceptive pill users: cohort evidence from Royal College of General Practitioners' Oral Contraception Study
}

\author{
Philip C Hannaford, Grampian Health Board chair of primary care, ${ }^{1}$ Lisa Iversen, research fellow, ${ }^{1}$ Tatiana V \\ Macfarlane, senior research fellow, ${ }^{2}$ Alison M Elliott, senior research fellow, ${ }^{1}$ Valerie Angus, data manager, ${ }^{3}$ \\ Amanda J Lee, professor of medical statistics ${ }^{4}$
}

${ }^{1}$ Centre of Academic Primary Care University of Aberdeen, Foresterhill Health Centre, Aberdeen AB25 2AY

${ }^{2}$ Division of Applied Medicine, University of Aberdeen, School of Medicine and Dentistry,

Foresterhill, Aberdeen AB25 2ZD ${ }^{3}$ College of Life Sciences and Medicine, Foresterhill, Aberdeen AB25 2ZD

${ }^{4}$ Medical Statistics Team, Section of Population Health, University of Aberdeen, Foresterhill, Aberdeen AB25 2ZD

Correspondence to: $\mathrm{P}$ Hannaford p.hannaford@abdn.ac.uk

Cite this as: BMJ 2010;340:c927 doi:10.1136/bmj.c927

\section{ABSTRACT}

Objective To see if the mortality risk among women who have used oral contraceptives differs from that of never users.

Design Prospective cohort study started in 1968 with mortality data supplied by participating general practitioners, National Health Service central registries, or both.

Setting 1400 general practices throughout the United Kingdom.

Participants 46112 women observed for up to 39 years, resulting in 378006 woman years of observation among never users of oral contraception and 819175 among ever users.

Main outcome measures Directly standardised adjusted relative risks between never and ever users for all cause and cause specific mortality.

Results 1747 deaths occurred in never users of oral contraception and 2864 in ever users. Compared with never users, ever users of oral contraception had a significantly lower rate of death from any cause (adjusted relative risk $0.88,95 \%$ confidence interval 0.82 to 0.93 ). They also had significantly lower rates of death from all cancers; large bowel/rectum, uterine body, and ovarian cancer; main gynaecological cancers combined; all circulatory disease; ischaemic heart disease; and all other diseases. They had higher rates of violent deaths. No association between overall mortality and duration of oral contraceptive use was observed, although some disease specific relations were apparent. An increased relative risk of death from any cause between ever users and never users was observed in women aged under 45 years who had stopped using oral contraceptives 5-9 years previously but not in those with more distant use. The estimated absolute reduction in all cause mortality among ever users of oral contraception was 52 per 100000 woman years.

Conclusion Oral contraception was not associated with an increased long term risk of death in this large UK cohort; indeed, a net benefit was apparent. The balance of risks and benefits, however, may vary globally, depending on patterns of oral contraception usage and background risk of disease.

\section{INTRODUCTION}

The Royal College of General Practitioners' (RCGP) Oral Contraception Study is one of the world's largest continuing investigations into the health effects of contraceptive pills. ${ }^{1}$ Early reports from the study indicated an increased risk of death among ever users of these contraceptives, mainly because of an excess of vascular events among older users or those who smoked. ${ }^{23} \mathrm{~A}$ later report, based on up to 25 years of follow-up, suggested that most of the mortality effects of oral contraceptives occurred in current or recent users, with few effects persisting beyond 10 years after stopping use. ${ }^{4}$ However, the median age of women at follow-up was only 49 years and relatively few deaths from each type of cancer had occurred. Prolonged follow-up was needed to determine how long any risks or benefits last after oral contraception is stopped. A recent publication from the study using incident cancer data has suggested that ever users of oral contraceptives may have a reduced overall risk of cancer. ${ }^{5}$ Whether this translates into an important mortality benefit, and if so how it relates to other causes of death, is unknown. We report the latest mortality findings from the RCGP Oral Contraception Study, based on up to 39 years of follow-up and nearly three times as many deaths as reported earlier. ${ }^{4}$

\section{METHODS}

The RCGP Oral Contraception Study started in May 1968 when 1400 general practitioners throughout the United Kingdom recruited approximately 23000 women who were using oral contraceptives and a similar number of women who had never used this method of birth control. ${ }^{1}$ All the women were married or living as married, most were white, and their mean age at recruitment was 29 (SD 6.6) years. Information collected at baseline included parity, smoking habits, social class (based on husband's occupation), and relevant medical history. The general practitioners subsequently supplied, at six monthly intervals, information about any hormonal preparations prescribed, any pregnancies and their outcome, all new episodes of 


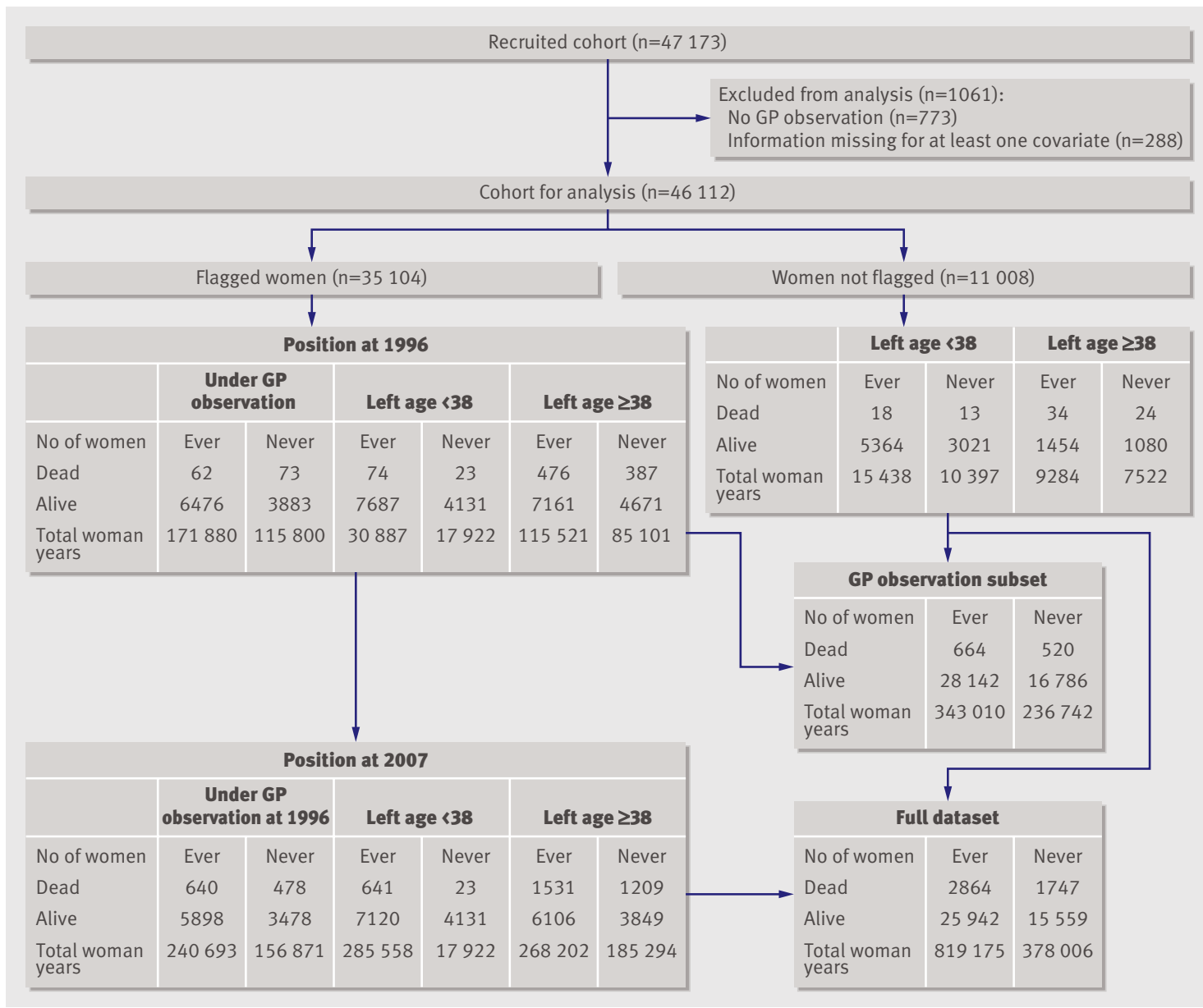

Flow chart of RCGP Oral Contraception Study

illness, any surgery, and any deaths occurring in women still under their observation. Women remained under general practice follow-up until they left the area of the recruiting doctor (approximately $56 \%$ of total cohort), the doctor left the study (13\%), they obtained their contraceptives from a source other than the general practitioner (3\%), they died $(2 \%)$, or the study stopped general practice follow-up at the end of $1996(26 \%)$.

In the mid 1970s, approximately three quarters of the original cohort ( $\mathrm{n}=35$ 104) were "flagged" at National Health Service central registries in Scotland and England, so that subsequent cancers and deaths would be reported to the study, even if the woman was no longer under general practice follow-up. The remaining $24 \%$ of women could not be flagged because they, or their general practitioner, left the study before flagging took place.

We assembled two datasets, both of which included data until the end of general practice follow-up on women who had not been flagged (figure). The full dataset also included periods of observation up to the date of death or June 2007 (whichever came first) for all flagged women still in the study when general practice follow-up ended in 1996, flagged never and ever oral contraceptive users lost to the study before 1996 who were aged 38 years or older at time of loss, and flagged ever users lost to the study before 1996 who were younger than 38 years at the time of loss. Flagged never users younger than 38 years and lost to general practice follow-up before 1996 were censored from the time of loss because we did not know whether the women subsequently started using oral contraceptives. We assumed that older never users were unlikely to have done so, as $91 \%$ of women in the study who used oral contraceptives started before the age of 38 . Never users in the full dataset, therefore, were women known, or assumed, to have never used oral contraceptives.

The general practice observation subset included periods of observation, deaths, and other relevant information obtained while women were under observation by general practitioners, up to their point of being lost to general practice follow-up, death, or December 1996 when general practice follow-up ended (whichever came first). This subset contained information about use of hormone replacement therapy while under general practice follow-up, as well as comprehensive data about the type and duration of oral contraceptives used.

The deaths were coded using ICD-8 (international classification of diseases, 8th revision). We grouped 
Table 1|Characteristics of women in ever used and never used oral contraceptive groups. Values are numbers (percentages) unless stated otherwise

\begin{tabular}{|c|c|c|c|}
\hline Characteristic & $\begin{array}{l}\text { Never users } \\
(n=17306)\end{array}$ & $\begin{array}{l}\text { Ever users } \\
(n=28806)\end{array}$ & $P$ value \\
\hline \multicolumn{4}{|c|}{ Age at recruitment (years): } \\
\hline$\ll 30$ & $8922(51.6)$ & $18323(63.6)$ & \multirow{4}{*}{$<0.001$} \\
\hline $30-39$ & $6605(38.2)$ & $8712(30.2)$ & \\
\hline $40-49$ & $1747(10.1)$ & $1748(6.1)$ & \\
\hline $50-59$ & $32(0.2)$ & $23(0.1)$ & \\
\hline \multicolumn{4}{|c|}{ Smoking at recruitment (cigarettes/day): } \\
\hline 0 & $10437(60.3)$ & $15081(52.4)$ & \multirow{3}{*}{$<0.001$} \\
\hline $1-14$ & $4188(24.2)$ & $7994(27.7)$ & \\
\hline$\geq 15$ & $2681(15.5)$ & 5731 (19.9) & \\
\hline \multicolumn{4}{|c|}{ Parity at recruitment: } \\
\hline 0 & $3490(20.2)$ & $4871(16.9)$ & \multirow{4}{*}{$<0.001$} \\
\hline 1 & $4497(26.0)$ & $6577(22.8)$ & \\
\hline 2 & $5495(31.7)$ & 9193 (31.9) & \\
\hline$\geq 3$ & $3824(22.1)$ & $8165(28.3)$ & \\
\hline \multicolumn{4}{|c|}{ Social class at recruitment: } \\
\hline Non-manual & $6680(38.6)$ & $10364(36.0)$ & \multirow{2}{*}{$<0.001$} \\
\hline Manual & $10626(61.4)$ & $18442(64.0)$ & \\
\hline \multicolumn{4}{|c|}{$\begin{array}{l}\text { Use of hormone replacement therapy } \\
\text { during general practice follow-up: }\end{array}$} \\
\hline Never & 15559 (89.9) & 25038 (86.9) & \multirow{2}{*}{$<0.001$} \\
\hline Ever & 1747 (10.1) & 3768 (13.1) & \\
\hline
\end{tabular}

Figures based on full dataset for age, smoking, parity, and social class, and on general practice observation subset for hormone replacement therapy use. them into individual cancer categories: large bowel and rectum (ICD-8 code 153-154), gallbladder and liver (155-156), lung (162), melanoma (172), breast (174), invasive cervix (180), uterine body (182), ovary (183), central nervous system and pituitary (191 and 1943), site unknown (199), and other cancers (any death coded between 140 and 209 not already mentioned); main gynaecological cancers combined (180, 182, and 183); any cancer (140-209); ischaemic heart disease (410-414), other heart (420-429), cerebrovascular disease (430-438), other circulatory (any death coded 390-458 not already mentioned); all circulatory disease combined (390-458); all digestive disease (520-577); liver disease (570-573); violent deaths (800-999, E800999); suicide (E950-959); all other causes (any death with a code not already mentioned); and any death (000-999, all E codes). These groupings were broadly similar to those used in our most recent mortality report, ${ }^{4}$ and we used them for ease of comparison.

Most deaths in the full dataset were notified by the central registries only $(75 \%$ (3437/4611) of all deaths). Of the 1184 deaths in the general practice observation subset, $160(14 \%)$ were notified by the general practitioner only, $25(2 \%)$ by the central registries only, and $999(84 \%)$ by both sources. If a discrepancy between sources occurred, we sought clarification from the general practitioner whenever possible. Three deaths occurred for which the event date differed by more than three months and 52 for which the discrepancy in dates was between one and three months. In each case, we used the information notified by the general practitioner. For 28 deaths, differences in the ICD-8 codes could not be reconciled, so we used the information notified by the general practitioner. On 12 occasions, date of death preceded other general practice observation data, and in these circumstances we assumed that the woman was still alive and removed the inconsistent date of death.

\section{Statistical analysis}

We used relative risk to measure associations between use of oral contraceptives and mortality. We aggregated deaths (numerator) and periods of observation (denominator) according to each woman's status at each calendar month while under general practice follow-up or that pertaining when she left such follow-up (except for age, which continued to change). We included women recruited as never users who subsequently started oral contraception in the pill user group from the date of starting.

We used the dstdize program in Stata 10.1 to calculate unadjusted and directly standardised death rates among ever users and never users of oral contraceptives. We standardised rates for the full dataset for smoking (0,1-14, $\geq 15$ cigarettes daily) and social class (non-manual, manual) at recruitment, parity $(0,1,2$, $\geq 3)$ at 1996 or time of death, and age group $(<30,30$ $39,40-49,50-59,60-69, \geq 70$ years) at 2007 or time of death. When analysing the general practice observation subset, we used the same variables (with collapsed age categories $(<39,40-49, \geq 50)$ for analyses of the duration of oral contraceptive use), in addition to use of hormone replacement therapy during general practice follow-up (never, ever). As higher mortality in older women may mask the effects of stopping oral contraception in younger women in the general practice observation subset, we examined risk of death by time since stopping oral contraception among women aged under 45 years, adjusting for age group $(<30,30-$ 34, 35-39, 40-44), parity, social class, and smoking. We used this cut-off age because few women in the cohort used hormone replacement therapy before the age of 45. We used the total population (ever users and never users) available for each analysis as the standard. As the standard populations and adjusting variables were different in each analysis, the results should not be compared directly.

We assumed approximate normality for the log of estimated relative risks when calculating 95\% confidence intervals. ${ }^{6}$ We calculated the log-linear test for trend for duration of oral contraception use by including each category as a metric explanatory variable with evenly spaced levels and using the Stata command stmh. We did not calculate trends for time since last use, as the data were too sparse for many categories of death. For clarity of presentation, we have shown only standardised rates for the analyses of duration of use and time since last use of oral contraception.

\section{RESULTS}

The full dataset contained more than 819000 woman years of observation for ever users and 378000 woman 
Table $2 \mid$ Risk of death among ever and never users of oral contraceptives in full dataset

\begin{tabular}{|c|c|c|c|c|c|c|}
\hline \multirow[b]{2}{*}{ Cause of death } & \multirow[b]{2}{*}{ ICD-8 codes } & \multicolumn{2}{|c|}{ Never users } & \multicolumn{2}{|c|}{ Ever users } & \multirow[b]{2}{*}{$\begin{array}{l}\text { Adjusted relative } \\
\text { risk† }(95 \% \mathrm{Cl})\end{array}$} \\
\hline & & $\begin{array}{l}\text { Observed rate } \\
\text { (No) }\end{array}$ & $\begin{array}{c}\text { Standardised } \\
\text { rate* }\end{array}$ & $\begin{array}{l}\text { Observed rate } \\
\text { (No) }\end{array}$ & $\begin{array}{c}\text { Standardised } \\
\text { rate* }\end{array}$ & \\
\hline All causes & 000-999, all E codes & $462.16(1747)$ & 417.45 & $349.62(2864)$ & 365.51 & $0.88(0.82$ to 0.93$)$ \\
\hline All cancers & $140-209$ & $205.29(776)$ & 194.55 & $160.16(1312)$ & 165.45 & 0.85 (0.78 to 0.93$)$ \\
\hline Large bowel and rectum & $153-154$ & $21.16(80)$ & 20.05 & $11.84(97)$ & 12.41 & 0.62 (0.46 to 0.83) \\
\hline Gallbladder/liver & $155-156$ & $3.17(12)$ & 3.12 & $1.83(15)$ & 2.03 & $0.65(0.30$ to 1.39$)$ \\
\hline Lung & 162 & $26.45(100)$ & 26.08 & $31.49(258)$ & 31.70 & 1.22 (0.96 to 1.53$)$ \\
\hline Melanoma & 172 & $2.65(10)$ & 2.67 & $1.95(16)$ & 1.95 & $0.73(0.33$ to 1.61$)$ \\
\hline Breast & 174 & $44.44(168)$ & 43.91 & $38.09(312)$ & 39.41 & $0.90(0.74$ to 1.08$)$ \\
\hline Invasive cervix & 180 & $3.70(14)$ & 4.02 & $5.62(46)$ & 5.38 & $1.34(0.74$ to 2.44$)$ \\
\hline Uterine body & 182 & $5.03(19)$ & 4.47 & $1.59(13)$ & 1.94 & $0.43(0.21$ to 0.88$)$ \\
\hline Ovary & 183 & $19.84(75)$ & 18.04 & $9.16(75)$ & 9.47 & 0.53 (0.38 to 0.72$)$ \\
\hline Main gynaecological & $180,182,183$ & $28.57(108)$ & 26.51 & $16.36(134)$ & 16.80 & 0.63 (0.49 to 0.82$)$ \\
\hline CNS-pituitary & 191,1943 & $5.03(19)$ & 4.47 & $3.42(28)$ & 3.74 & $0.84(0.47$ to 1.50$)$ \\
\hline Site unknown & 199 & $22.22(84)$ & 20.50 & $17.21(141)$ & 18.02 & $0.88(0.67$ to 1.15$)$ \\
\hline Other cancers & 140-209, except above & 51.59 (195) & 47.19 & $37.96(311)$ & 39.39 & $0.83(0.70$ to 1.00$)$ \\
\hline All circulatory diseases & $390-458$ & $132.54(501)$ & 115.18 & $93.14(763)$ & 99.15 & $0.86(0.77$ to 0.96$)$ \\
\hline Ischaemic heart disease & $410-414$ & $64.02(242)$ & 57.41 & $41.02(336)$ & 42.85 & 0.75 (0.63 to 0.88$)$ \\
\hline Other heart & $420-429$ & $15.34(58)$ & 11.90 & $9.03(74)$ & 10.12 & $0.85(0.60$ to 1.20$)$ \\
\hline Cerebrovascular disease & $430-438$ & $32.54(123)$ & 27.86 & 27.71(227) & 29.19 & 1.05 (0.84 to 1.30$)$ \\
\hline Other circulatory & $390-409,440-458$ & $20.63(78)$ & 18.02 & $15.38(126)$ & 16.98 & $0.94(0.71$ to 1.25$)$ \\
\hline All digestive disease & $520-577$ & $18.25(69)$ & 16.53 & $15.38(126)$ & 15.67 & $0.95(0.71$ to 1.27$)$ \\
\hline Liver disease & $570-573$ & $5.56(21)$ & 5.48 & $7.20(59)$ & 7.20 & $1.32(0.80$ to 2.16$)$ \\
\hline Violence & 800-999, E800-999 & $13.49(51)$ & 12.86 & $19.04(156)$ & 19.20 & 1.49 (1.09 to 2.05$)$ \\
\hline Suicide & E950-959 & $4.50(17)$ & 4.79 & $6.10(50)$ & 6.03 & $1.26(0.73$ to 2.18$)$ \\
\hline All other diseases & All codes, except above & $92.06(348)$ & 77.80 & $61.4(503)$ & 65.59 & 0.84 (0.74 to 0.97) \\
\hline
\end{tabular}

years for never users. The corresponding figures for the general practice observation subset were 343000 and 237000 woman years. Compared with never users, ever users tended to be younger, smokers, and of higher parity and manual social class at recruitment and to have used hormone replacement therapy while under general practice observation (table 1).

In the full dataset, all cause mortality among ever users of oral contraception was $12 \%$ lower than that of never users (adjusted relative risk 0.88, 95\% confidence interval 0.82 to 0.93 ) (table 2). We found significantly lower rates among ever users of deaths from all cancers; cancer of the large bowel/rectum, uterine body, or ovaries; main gynaecological cancers combined; all circulatory disease; ischaemic heart disease; and all other diseases. The all other diseases category included 445 respiratory conditions, 72 nervous system and sense organ conditions, 68 infective and parasitic disorders, 55 symptoms and ill defined conditions, 51 mental disorders, 47 genitourinary disorders, and 41 endocrine and metabolic disorders. Ever users of oral contraceptives also had a significantly higher rate of violent death.

All cause mortality increased with age and smoking in both ever users and never users of oral contraceptives (table 3 ). In the youngest $(<30$ years) age group, ever users of oral contraceptives had an almost threefold greater rate of any death than did never users (adjusted relative risk 2.85, 1.17 to 6.94 ). From the age of 50, however, the rate of any death among ever users of oral contraceptives was significantly lower than that in never users. In all categories of smoking, social class, and parity, ever users of oral contraception had lower all cause mortality than did never users, although not all of the relative risk estimates were statistically significant.

The pattern of relative risks was different when we used the smaller general practice observation subset (table 4). In this subset, the adjusted relative risk for any death between ever users and never users was very close to unity $(0.98,0.88$ to 1.10$)$. Compared with never users, ever users had a significantly lower rate of death from ovarian cancer, main gynaecological cancers combined, and all other diseases and a higher rate of death from all circulatory disease, cerebrovascular disease, other circulatory disease, and violence.

The median duration of oral contraceptive use in the study was 44 (range 1-344, interquartile range 19-83) months. We found no consistent pattern of materially different all cause mortality among women who had used oral contraception for different durations, when 
Table $3 \mid$ Risk of all cause mortality among ever and never users of different age, parity, smoking, and social class in full dataset

\begin{tabular}{|c|c|c|c|}
\hline \multirow[b]{2}{*}{ Variable } & \multicolumn{2}{|c|}{ Standardised rate* $(\mathrm{No})$} & \multirow{2}{*}{$\begin{array}{l}\text { Adjusted relative risk } \dagger \\
(95 \% \mathrm{Cl})\end{array}$} \\
\hline & Never users & Ever users & \\
\hline \multicolumn{4}{|l|}{ Age (years): } \\
\hline$\ll 30$ & $11.04(6)$ & $31.44(25)$ & 2.85 (1.17 to 6.94$)$ \\
\hline $30-39$ & $69.21(50)$ & $73.21(133)$ & 1.06 (0.76 to 1.46$)$ \\
\hline $40-49$ & $183.74(159)$ & $170.17(368)$ & 0.93 (0.77 to 1.12$)$ \\
\hline 50-59 & $469.33(393)$ & $382.88(812)$ & 0.82 (0.72 to 0.92$)$ \\
\hline $60-69$ & $916.23(569)$ & $794.48(916)$ & $0.87(0.78$ to 0.96$)$ \\
\hline $70+$ & $2461.20(570)$ & $2153.44(610)$ & 0.87 (0.78 to 0.98$)$ \\
\hline \multicolumn{4}{|c|}{ Smoking (No of cigarettes/day): } \\
\hline 0 & $307.03(798)$ & $248.09(1021)$ & 0.81 (0.74 to 0.89 ) \\
\hline $1-14$ & 448.95 (474) & $408.00(842)$ & 0.91 (0.81 to 1.02$)$ \\
\hline$\geq 15$ & $718.23(475)$ & $664.48(1001)$ & 0.93 (0.83 to 1.03$)$ \\
\hline \multicolumn{4}{|l|}{ Social class: } \\
\hline Non-manual & $357.82(570)$ & 325.20 (929) & 0.91 (0.82 to 1.01$)$ \\
\hline Manual & $453.08(1177)$ & 386.59 (1935) & 0.85 (0.79 to 0.92$)$ \\
\hline \multicolumn{4}{|l|}{ Parity: } \\
\hline 0 & $502.18(177)$ & $362.13(146)$ & 0.72 (0.58 to 0.90$)$ \\
\hline 1 & $416.53(291)$ & $366.10(347)$ & 0.88 (0.75 to 1.03$)$ \\
\hline 2 & $378.89(572)$ & $334.08(946)$ & 0.88 (0.79 to 0.98$)$ \\
\hline$\geq 3$ & $439.05(707)$ & 388.33 (1425) & 0.88 (0.81 to 0.97$)$ \\
\hline
\end{tabular}

*Standardised rate per 100000 woman years, adjusted for age, parity, smoking, and social class, except where variable itself is being examined.

†Baseline=never users. suggested an overall reduction in mortality, resulting from lower rates of different specific causes of death, including cancer and circulatory disease. A higher rate of violent or accidental death among oral contraceptive users than among never users has been noted in the cohort before and seems to be persisting. ${ }^{1-3}$

\section{Strengths and limitations of study}

A major strength of the study was the ability to include more than a million woman years of observation, accumulated over a 39 year period and involving nearly three times as many deaths (a total of more than 4600 ) as before. ${ }^{4} \mathrm{~A}$ previous study has shown good agreement between the cause of death reported by the general practitioners and that on the death certificate. $^{7}$ Although both sources of information are prone to error in the attribution of underlying cause of death, we have no reason to suspect systematic differences because of a woman's use (or not) of oral contraception. This is especially so for more recent events, for which most of the doctors certifying the deaths will have been unaware of the contraceptive history of the deceased woman.

We were able to adjust for the potentially important confounding factors of age, smoking, social class, parity, and (for some analyses of the general practice observation subset) use of hormone replacement therapy. The adjustments tended to make little difference to the rates. Smoking data have not been routinely updated during the study. Use of smoking information collected at study entry will tend to underestimate the effects of smoking. This is because women in the cohort are more likely to have stopped smoking than started since recruitment, so disproportionately more women will be misclassified in the smoker group with a decreased risk of smoking related death than in the non-smoker group at increased risk of such an event. Furthermore, a study of a subgroup of approximately 10000 women who completed a health survey in the mid-1990s produced virtually identical estimates of risk for myocardial infarction associated with oral contraceptive use based on updated smoking data to those based on information collected at recruitment. ${ }^{8}$ As we were unable to adjust our results for other lifestyle or familial variables, residual confounding must remain an alternative explanation for our findings.

The study has been prone to large losses to followup; the full dataset contains approximately two thirds of an estimated 1800000 woman years of observation that would have occurred if nobody had been lost to follow-up. Biased results could have occurred if a relation existed between leaving the study, use of the contraceptive pill, and risk of death. A previous analysis has shown that women lost to general practice followup had similar risks of death to those still under observation, ${ }^{9}$ suggesting no major systematic bias from loss to follow-up. To investigate whether our results for the full dataset were affected by the censoring of flagged never users younger than 38 years when lost to general practice follow-up before 1996, we did a sensitivity analysis in which we excluded both flagged 
Table 4 |Risk of death among ever and never users of oral contraceptives in general practice observation subset

\begin{tabular}{|c|c|c|c|c|c|c|}
\hline \multirow[b]{2}{*}{ Cause of death } & \multirow[b]{2}{*}{ ICD-8 code } & \multicolumn{2}{|c|}{ Never users } & \multicolumn{2}{|c|}{ Ever users } & \multirow[b]{2}{*}{$\begin{array}{l}\text { Adjusted relative } \\
\text { risk† }(95 \% \mathrm{Cl})\end{array}$} \\
\hline & & $\begin{array}{l}\text { Observed rate } \\
\text { (No) }\end{array}$ & $\begin{array}{l}\text { Standardised } \\
\text { rate* }^{\star}\end{array}$ & $\begin{array}{l}\text { Observed rate } \\
\text { (No) }\end{array}$ & $\begin{array}{l}\text { Standardised } \\
\text { rate }^{\star}\end{array}$ & \\
\hline All causes & 000-999, all E codes & $219.65(520)$ & 206.51 & $193.58(664)$ & 203.20 & 0.98 (0.88 to 1.10$)$ \\
\hline All cancers & $140-209$ & $120.38(285)$ & 116.71 & $95.91(329)$ & 103.26 & 0.88 (0.75 to 1.04$)$ \\
\hline Large bowel and rectum & 153-154 & $12.25(29)$ & 11.83 & $7.00(24)$ & 8.28 & 0.70 (0.41 to 1.20$)$ \\
\hline Gallbladder/liver & $155-156$ & $1.69(4)$ & 1.52 & $1.46(5)$ & 2.13 & $1.40(0.38$ to 5.21$)$ \\
\hline Lung & 162 & $13.52(32)$ & 15.54 & $15.16(52)$ & 16.30 & 1.05 (0.67 to 1.63$)$ \\
\hline Melanoma & 172 & $2.53(6)$ & 2.32 & $2.04(7)$ & 1.98 & 0.85 (0.29 to 2.54$)$ \\
\hline Breast & 174 & $35.48(84)$ & 34.38 & $30.32(104)$ & 32.36 & 0.94 (0.71 to 1.25$)$ \\
\hline Invasive cervix & 180 & $3.38(8)$ & 3.63 & $5.54(19)$ & 5.54 & 1.52 (0.67 to 3.48$)$ \\
\hline Uterine body & 182 & $2.53(6)$ & 2.11 & $0.29(1)$ & 0.26 & 0.12 (0.01 to 1.03$)$ \\
\hline Ovary & 183 & $12.25(29)$ & 11.11 & $4.08(14)$ & 4.78 & $0.43(0.23$ to 0.81$)$ \\
\hline Main gynaecological & $180,182,183$ & $18.16(43)$ & 16.85 & $9.91(34)$ & 10.58 & 0.63 (0.40 to 0.98$)$ \\
\hline CNS-pituitary & 191,1943 & $0.84(2)$ & 0.72 & $2.62(9)$ & 2.54 & 3.53 (0.76 to 16.35$)$ \\
\hline Site unknown & 199 & $8.45(20)$ & 7.56 & $3.50(12)$ & 3.79 & 0.50 (0.25 to 1.03$)$ \\
\hline Other cancers & 140-209, except above & $27.46(65)$ & 25.98 & $23.91(82)$ & 25.30 & 0.97 (0.70 to 1.35$)$ \\
\hline All circulatory disease & $390-458$ & $42.24(100)$ & 37.76 & $51.02(175)$ & 51.83 & 1.37 (1.07 to 1.75$)$ \\
\hline Ischaemic heart disease & $410-414$ & $21.12(50)$ & 19.43 & $18.37(63)$ & 19.56 & 1.01 (0.69 to 1.46$)$ \\
\hline Other heart & $420-429$ & $3.38(8)$ & 2.66 & $4.37(15)$ & 4.84 & 1.82 (0.77 to 4.29$)$ \\
\hline Cerebrovascular disease & $430-438$ & $13.94(33)$ & 12.50 & $19.82(68)$ & 18.89 & 1.51 (1.00 to 2.29$)$ \\
\hline Other circulatory & $390-409,440-458$ & $3.80(9)$ & 3.17 & $8.45(29)$ & 8.54 & 2.70 (1.28 to 5.70$)$ \\
\hline All digestive disease & $520-577$ & $9.29(22)$ & 7.65 & $6.41(22)$ & 6.50 & 0.85 (0.47 to 1.54$)$ \\
\hline Liver disease & $570-573$ & $4.22(10)$ & 3.63 & $3.79(13)$ & 3.99 & 1.10 (0.48 to 2.51$)$ \\
\hline Violence & 800-999, E800-999 & $10.98(26)$ & 10.64 & $19.82(68)$ & 20.41 & $1.92(1.22$ to 3.01$)$ \\
\hline Suicide & E950-959 & $5.49(13)$ & 5.66 & $8.45(29)$ & 8.80 & 1.56 (0.81 to 2.99$)$ \\
\hline All other diseases & $\begin{array}{c}\text { All codes, except } \\
\text { above }\end{array}$ & $35.90(85)$ & 32.78 & $19.53(67)$ & 20.41 & 0.62 (0.45 to 0.86$)$ \\
\hline
\end{tabular}

CNS=central nervous system; ICD-8=international classification of diseases, version 8.

*Standardised rate per 100000 woman years, adjusted for age, parity, smoking, social class, and use of hormone replacement therapy. †Baseline=never users.

ever users and flagged never users who met these criteria. The adjusted relative risk for any death was 0.91 (95\% confidence interval 0.86 to 0.97 ). The pattern of relative risks for specific causes of death also tended to be very similar to that of the full dataset.

The analyses may have been prone to misclassification of exposure, as we assumed that never users older than 38 years who left the study did not subsequently start oral contraception. The level of misclassification is likely to have been small, and its effect will have been to underestimate the oral contraception related risk of death.

Recent experience of the strikingly different results between observational and randomised experimental data on the cardiovascular effects of hormone replacement therapy provides a powerful reminder of the need for care when interpreting observational epidemiological data. ${ }^{10}$ In addition to residual confounding, healthy survivorship is another possible explanation for the observed overall reduced risk of death among ever users. Our cohort is certainly healthier than the national average - in 1999 the standardised mortality ratio was $79,{ }^{4}$ mainly because women with chronic disease were not recruited to the study. ${ }^{1}$ For this to have contributed to our results, differential survivorship would have had to occur between women using and not using oral contraceptives. Although speculating about how such an effect might have occurred is interesting (for example, through a beneficial effect of regular blood pressure and other monitoring during and possibly after use of oral contraception), a clear mechanism is not apparent, especially one that would affect different outcomes, including cancer and circulatory disease.

We did not examine whether risk of death differed according to the hormonal content of the contraceptive pills used. Most (75\%) of the pills used in the study contained $50 \mu \mathrm{g}$ of oestrogen $(>50 \mu \mathrm{g}$ products $12 \%$, $<50 \mu \mathrm{g}$ formulations $10 \%$, progestogen only preparations 3\%). Most women used preparations from more than one category of oestrogen dose, almost entirely in a downwards direction - for example, from a $>50 \mu \mathrm{g}$ preparation to a $50 \mu \mathrm{g}$ preparation. Lack of exclusive use of any particular dose category means that we cannot know whether any associations between death and oestrogen dosage are due to the effects of the preparation used most recently before death or lingering effects from a previously used (usually higher dose) formulation.

\section{Comparison with other studies}

Two other large, long term cohort studies have found no significant overall increased risk of death among 
Table $5 \mid$ Risk of death by duration of oral contraceptive use in general practice observation subset

\begin{tabular}{|c|c|c|c|c|c|c|c|}
\hline \multirow[b]{3}{*}{ Cause of death } & \multirow{3}{*}{$\begin{array}{c}\text { Rate (No) } \\
\text { in never users }\end{array}$} & \multicolumn{6}{|c|}{ Duration of oral contraceptive use } \\
\hline & & \multicolumn{2}{|c|}{$\ll 4$ years } & \multicolumn{2}{|c|}{ 4-8 years } & \multicolumn{2}{|c|}{$\geq 8$ years } \\
\hline & & Rate* $^{\star}$ No) & ARR† $(95 \% \mathrm{Cl})$ & Rate $^{\star}($ No) & ARR† $(95 \% \mathrm{Cl})$ & $\operatorname{Rate}^{\star}(\mathrm{No})$ & ARR† $(95 \% \mathrm{Cl})$ \\
\hline All causes & $210.10(520)$ & $191.98(247)$ & $0.91(0.79$ to 1.06$)$ & $215.66(220)$ & $1.03(0.88$ to 1.20$)$ & $211.00(197)$ & 1.00 (0.85 to 1.18$)$ \\
\hline All cancers & $117.98(285)$ & $103.99(126)$ & 0.88 (0.71 to 1.09 ) & $92.66(96)$ & $0.79(0.62$ to 0.99$)$ & $113.44(107)$ & 0.96 (0.77 to 1.20$)$ \\
\hline Large bowel and rectum & $11.83(29)$ & $12.07(12)$ & 1.02 (0.52 to 2.00$)$ & $7.71(8)$ & 0.65 (0.30 to 1.43$)$ & $5.34(4)$ & 0.45 (0.16 to 1.28$)$ \\
\hline Gallbladder/liver & $1.48(4)$ & $2.45(2)$ & $1.66(0.30$ to 9.04$)$ & $1.17(1)$ & 0.79 (0.09 to 7.08$)$ & $2.33(2)$ & 1.57 (0.29 to 8.59$)$ \\
\hline Lung & $15.21(32)$ & $17.14(20)$ & $1.13(0.64$ to 1.97$)$ & $9.95(11)$ & 0.65 (0.33 to 1.30$)$ & $17.79(21)$ & 1.17 (0.67 to 2.03 ) \\
\hline Melanoma & $2.32(6)$ & $2.81(4)$ & $1.21(0.34$ to 4.28$)$ & $0.78(1)$ & 0.34 (0.04 to 2.79 ) & $1.64(2)$ & 0.71 (0.14 to 3.50$)$ \\
\hline Breast & $34.59(84)$ & $31.96(41)$ & $0.92(0.64$ to 1.34$)$ & $30.04(31)$ & 0.87 (0.58 to 1.31$)$ & $39.13(32)$ & 1.13 (0.75 to 1.70$)$ \\
\hline Invasive cervix & $3.59(8)$ & $3.88(5)$ & $1.08(0.35$ to 3.31$)$ & $5.75(6)$ & 1.60 (0.56 to 4.62$)$ & $10.67(8)$ & 2.97 (1.12 to 7.92$)$ \\
\hline Uterine body & $2.15(6)$ & $0.90(1)$ & 0.42 (0.05 to 3.45$)$ & $-(0)$ & - & $-(0)$ & - \\
\hline Ovary & $11.53(29)$ & $5.20(7)$ & $0.45(0.20$ to 1.03$)$ & $2.73(3)$ & 0.24 (0.07 to 0.78$)$ & 3.97 (4) & 0.34 (0.12 to 0.98$)$ \\
\hline Main gynaecological & $17.32(43)$ & $9.98(13)$ & $0.58(0.31$ to 1.07$)$ & $8.49(9)$ & 0.49 (0.24 to 1.01$)$ & $14.78(12)$ & 0.85 (0.45 to 1.62$)$ \\
\hline CNS-pituitary & $0.68(2)$ & $0.66(1)$ & 0.97 (0.09 to 10.72$)$ & $4.58(5)$ & 6.78 (1.32 to 34.96$)$ & $2.19(3)$ & 3.24 (0.54 to 19.39$)$ \\
\hline Site unknown & $7.77(20)$ & $4.84(6)$ & $0.62(0.25$ to 1.55$)$ & $-(0)$ & - & $5.88(6)$ & 0.76 (0.30 to 1.89$)$ \\
\hline Other cancers & $26.78(65)$ & $22.04(27)$ & $0.82(0.53$ to 1.29$)$ & $29.85(30)$ & 1.11 (0.72 to 1.72$)$ & $24.49(25)$ & 0.91 (0.58 to 1.45$)$ \\
\hline All circulatory disease & $39.37(100)$ & $47.13(61)$ & $1.20(0.87$ to 1.65$)$ & $71.89(71)$ & 1.83 (1.35 to 2.48$)$ & $42.69(43)$ & 1.08 (0.76 to 1.55$)$ \\
\hline Ischaemic heart disease & $19.94(50)$ & $19.65(22)$ & 0.99 (0.60 to 1.63$)$ & $33.85(32)$ & 1.70 (1.09 to 2.65$)$ & $7.94(9)$ & 0.40 (0.20 to 0.81$)$ \\
\hline Other heart & 3.34 (8) & $4.12(5)$ & 1.24 (0.40 to 3.78$)$ & $8.00(6)$ & $2.40(0.83$ to 6.91$)$ & $4.65(4)$ & 1.39 (0.42 to 4.63$)$ \\
\hline Cerebrovascular disease & $12.67(33)$ & $16.19(22)$ & 1.28 (0.74 to 2.19$)$ & $22.82(26)$ & 1.80 (1.08 to 3.01$)$ & $20.11(20)$ & 1.59 (0.91 to 2.77 ) \\
\hline Other circulatory & $3.42(9)$ & $7.17(12)$ & 2.09 (0.88 to 4.97$)$ & $7.22(7)$ & 2.11 (0.79 to 5.66$)$ & $9.99(10)$ & 2.92 (1.19 to 7.18$)$ \\
\hline All digestive disease & $7.73(22)$ & $4.30(6)$ & $0.56(0.23$ to 1.37$)$ & $7.80(9)$ & 1.01 (0.46 to 2.19$)$ & $6.57(7)$ & 0.85 (0.36 to 1.99$)$ \\
\hline Liver disease & $3.59(10)$ & $2.99(4)$ & $0.83(0.26$ to 2.65$)$ & $2.83(3)$ & 0.79 (0.22 to 2.86$)$ & $5.88(6)$ & 1.64 (0.60 to 4.51$)$ \\
\hline Violence & $10.6(26)$ & $20.61(32)$ & 1.94 (1.16 to 3.26$)$ & $20.39(21)$ & 1.92 (1.08 to 3.42$)$ & $22.85(15)$ & 2.16 (1.14 to 4.07$)$ \\
\hline Suicide & $5.62(13)$ & $7.88(12)$ & 1.40 (0.64 to 3.08$)$ & $11.02(12)$ & $1.96(0.90$ to 4.30$)$ & $12.04(5)$ & 2.14 (0.76 to 6.01$)$ \\
\hline All other diseases & $33.45(85)$ & $15.47(21)$ & $0.46(0.29$ to 0.75$)$ & $21.85(22)$ & 0.65 (0.41 to 1.04$)$ & $24.77(24)$ & 0.74 (0.47 to 1.16$)$ \\
\hline
\end{tabular}

ARR=adjusted relative risk; $C N S=$ central nervous system.

*Standardised rate per 100000 woman years, adjusted for age, parity, smoking, social class, and use of hormone replacement therapy.

†Adjusted relative risk with never users as baseline.

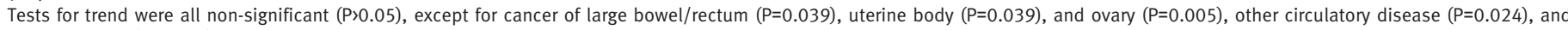
violent deaths $(P=0.026)$.

ever users compared with never users of oral contraception. ${ }^{112}$ The North American Nurses' Health Study reported results relating to 2879 deaths occurring during 1.3 million woman years of observation accumulated between 1976 and 1988 (adjusted relative risk in ever users $0.93,0.85$ to 1.10$).{ }^{11}$ Most oral contraceptive users in the Nurses Health Study were past users, so its results are most comparable with our full dataset results. The adjusted relative risks for deaths due to cancer $(0.92,0.81$ to 1.03$)$ and cardiovascular disease $(0.86,0.71$ to 1.05$)$ were also very similar to the results of our full dataset. This is reassuring given that the background risk of disease, and the associated physical, psychosocial, and cultural risk factors, differ between women living on either side of the Atlantic.

Results from the smaller UK Oxford Family Planning Association Contraception Study, based on 889 deaths recorded during nearly 0.5 million woman years of observation between 1968 and 2000, were also very similar to the results of our full dataset (adjusted relative risk in ever users $0.89,0.77$ to 1.02$).{ }^{12}$ Although our findings for cause specific deaths are broadly in line with the Oxford study, we found a lower risk of death from cervical cancer among ever users.
We are unable to explain the increased risk of violent and accidental deaths in our study among ever users of oral contraceptives. The persistence of this effect is noteworthy. The Nurses Health Study and the Oxford study did not find a significantly increased risk of death from suicide and trauma or from accidents and violence. $^{1112}$

As all of the cohorts have aged, the proportion of periods of observation among ever users due to current and recent use has decreased, thereby diminishing the contribution that short term risks among current and recent users make to the overall risk within ever users. Over time, the overall relative risk of death in the RCGP study has diminished from 1.4 in 1977 to 1.0 in $1999,{ }^{24}$ and then to 0.88 in the full dataset in this report. These observations provide an important reminder that perceptions about the safety of oral contraception will be heavily influenced by whether current, recent, or more distant use is being assessed.

\section{Conclusions and policy implications}

Our results do not suggest a persisting or emerging mortality risk over time among women who have used oral contraceptives. The reduced rate of cancer seen among the cohort when incident data were used 
Table $6 \mid$ Risk of death by time since last oral contraceptive use in women aged 445 years in general practice observation subset

\begin{tabular}{|c|c|c|c|c|c|c|c|}
\hline & \multirow{3}{*}{$\begin{array}{c}\text { Rate* (No) }^{*} \\
\text { in never users }\end{array}$} & \multicolumn{6}{|c|}{ Time since last oral contraceptive use } \\
\hline & & \multicolumn{2}{|c|}{ Current and $<5$ years } & \multicolumn{2}{|c|}{ 5-9 years } & \multicolumn{2}{|c|}{$\geq 10$ years } \\
\hline & & 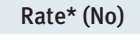 & ARR† $(95 \% \mathrm{Cl})$ & 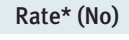 & ARR† $(95 \% \mathrm{Cl})$ & Rate $^{\star}\left(\mathrm{No}_{0}\right)$ & ARR† $(95 \% \mathrm{Cl})$ \\
\hline All causes & $69.80(103)$ & 75.49 (124) & 1.08 (0.83 to 1.40$)$ & $123.0(53)$ & 1.76 (1.27 to 2.45$)$ & $67.40(22)$ & 0.97 (0.61 to 1.53$)$ \\
\hline All cancers & $36.11(52)$ & $29.66(43)$ & $0.82(0.55$ to 1.23$)$ & $68.86(25)$ & 1.91 (1.18 to 3.07$)$ & $14.13(6)$ & 0.39 (0.17 to 0.91$)$ \\
\hline Large bowel and rectum & $3.75(5)$ & $2.13(3)$ & 0.57 (0.14 to 2.37 ) & $-(0)$ & - & 4.89 (1) & 1.30 (0.15 to 11.16$)$ \\
\hline Gallbladder/liver & $-(0)$ & $-(0)$ & - & $3.53(1)$ & - & $-(0)$ & - \\
\hline Lung & $3.15(4)$ & $3.25(4)$ & 1.03 (0.26 to 4.12$)$ & $3.24(2)$ & 1.03 (0.19 to 5.61$)$ & $-(0)$ & - \\
\hline Melanoma & $1.41(2)$ & $1.23(2)$ & 0.88 (0.12 to 6.21$)$ & $-(0)$ & - & $-(0)$ & - \\
\hline Breast & $10.72(16)$ & $11.92(17)$ & 1.11 (0.56 to 2.20 ) & $32.08(12)$ & 2.99 (1.42 to 6.33) & $1.63(1)$ & $0.15(0.02$ to 1.15$)$ \\
\hline Invasive cervix & $1.67(2)$ & $3.13(5)$ & 1.87 (0.36 to 9.65$)$ & $8.24(3)$ & 4.92 (0.82 to 29.44) & $3.26(2)$ & 1.95 (0.27 to 13.83$)$ \\
\hline Uterine body & $-(0)$ & $-(0)$ & - & $-(0)$ & - & $-(0)$ & - \\
\hline Ovary & $3.08(5)$ & $1.01(1)$ & 0.33 (0.04 to 2.80$)$ & $5.30(2)$ & $1.72(0.33$ to 8.86$)$ & $1.63(1)$ & 0.53 (0.06 to 4.53$)$ \\
\hline Main gynaecological & $4.76(7)$ & $4.20(6)$ & $0.88(0.30$ to 2.63$)$ & $13.54(5)$ & $2.85(0.90$ to 8.97$)$ & $4.89(3)$ & 1.03 (0.27 to 3.98$)$ \\
\hline CNS-pituitary & $-(0)$ & $-(0)$ & - & 1.77 (1) & - & $-(0)$ & - \\
\hline Site unknown & $-(0)$ & $-(0)$ & - & $-(0)$ & - & $-(0)$ & - \\
\hline Other cancers & $12.33(18)$ & $7.00(11)$ & $0.57(0.27$ to 1.20$)$ & $14.71(4)$ & 1.19 (0.40 to 3.53$)$ & $2.72(1)$ & $0.22(0.03$ to 1.65$)$ \\
\hline All circulatory disease & $9.18(14)$ & $18.69(31)$ & 2.04 (1.08 to 3.83 ) & 28.25 (15) & 3.08 (1.49 to 6.38 ) & $21.20(8)$ & 2.31 (0.97 to 5.51$)$ \\
\hline Ischaemic heart disease & $3.89(5)$ & $5.43(7)$ & 1.40 (0.44 to 4.40$)$ & $3.24(2)$ & 0.83 (0.16 to 4.29) & $-(0)$ & - \\
\hline Other heart & $0.40(1)$ & $1.73(3)$ & $4.32(0.45$ to 41.49$)$ & $-(0)$ & - & $-(0)$ & - \\
\hline Cerebrovascular disease & $4.89(8)$ & $7.83(14)$ & $1.60(0.67$ to 3.82$)$ & $18.24(10)$ & 3.73 (1.47 to 9.45$)$ & $5.98(5)$ & $1.22(0.40$ to 3.74$)$ \\
\hline Other circulatory & $-(0)$ & $3.69(7)$ & - & $7.06(3)$ & - & $15.22(3)$ & - \\
\hline All digestive disease & $2.08(4)$ & $3.64(6)$ & 1.75 (0.49 to 6.21$)$ & 5.89 (3) & 2.83 (0.63 to 12.66 ) & $-(0)$ & - \\
\hline Liver disease & $1.67(3)$ & $2.46(3)$ & $1.47(0.30$ to 7.28$)$ & $5.89(3)$ & 3.51 (0.71 to 17.41$)$ & $-(0)$ & - \\
\hline Violence & $10.38(15)$ & $14.55(28)$ & $1.40(0.75$ to 2.62$)$ & $12.36(6)$ & 1.19 (0.46 to 3.07$)$ & $16.85(3)$ & $1.62(0.47$ to 5.61$)$ \\
\hline Suicide & $5.49(7)$ & 7.39 (14) & 1.34 (0.54 to 3.33$)$ & $7.36(3)$ & 1.34 (0.35 to 5.18$)$ & $5.44(1)$ & $0.99(0.12$ to 8.04$)$ \\
\hline All other diseases & $11.39(17)$ & $8.95(16)$ & 0.79 (0.40 to 1.56$)$ & $7.65(4)$ & 0.67 (0.23 to 2.00$)$ & $14.68(5)$ & 1.29 (0.48 to 3.49$)$ \\
\hline
\end{tabular}

has been accompanied by a reduced risk of death from cancer, principally through long term reductions in large bowel/rectum, uterine body, and ovarian cancers. ${ }^{5}$ Many women, especially those who used the first generation of oral contraceptives many years ago, are likely to be reassured by our results. However, our findings might not reflect the experience of women using oral contraceptives today, if currently available preparations have a different risk than earlier products or if differences in patterns of usage (such as age at starting or duration of use) materially affect mortality risk.

From the full dataset, the estimated overall absolute reduction in mortality among ever users of oral contraception was 52 per 100000 woman years, with larger benefits in older women outweighing more modest excess risks among younger women (20 more deaths per 100000 woman years at age $<30,4$ more deaths per 100000 at age 30-39, 14 fewer deaths per 100000 at age 40-49, 86 fewer deaths per 100000 at age 50-59, 122 fewer deaths per 100000 at age 60-69, and 308 fewer deaths per 100000 at age $\geq 70$ ). Although the proportion of increases or decreases in mortality directly attributable to oral contraception cannot be determined, these figures indicate that, at least in this relatively healthy UK cohort, oral contraception is not significantly associated with a major public health problem. The level of reduction in mortality seen in different parts of the world will depend on factors such as levels of oral contraception usage, duration of use, age at stopping, and the prevalence of disease.

\section{WHAT IS ALREADY KNOWN ON THIS TOPIC}

Most of the mortality risks associated with oral contraception seem to disappear within about 10 years of stopping

Ever users of oral contraception have a reduced overall risk of incident cancer, but whether this translates into an important mortality benefit is not known

\section{WHAT THIS STUDY ADDS}

Perceptions about the safety of oral contraception depend on whether current, recent, or more distant use of oral contraception is being assessed

Oral contraception was not associated with an increased long term risk of death in this UK cohort and may even produce a net benefit (absolute risk reduction among ever users 52 per 100000 woman years)

The balance of risks and benefits, however, may vary around the world, depending on patterns of oral contraception usage and the prevalence of different diseases 
This paper would not have been possible without the leadership of Clifford Kay, who established and ran the study for its first 26 years, or the many general practitioners who contributed data. Wealso thankAileen Murphyfor databaseadministrationsupportand Sivasubramaniam Selvarajwhowrote most of the programming in Stata.

Contributors: PCH had the original idea, advised on and checked the analyses, and wrote the first and subsequent drafts of the paper. LI and AME had responsibility for updating the database with information on deaths. LI and VA checked the data extractions and analyses. TM was responsible for data analysis. AJL, with AME, checked the validity of the program used to analyse the data. VA maintained the study database and extracted data for analysis. All authors contributed to the scientific development of the paper, commented on successive drafts, and agreed to the final manuscript. PCH is the guarantor.

Funding: The study received funding from the Royal College of General Practitioners, Medical Research Council, Imperial Cancer Research Fund British Heart Foundation, Cruden Foundation, Schering AG, Schering Health Care, Wyeth Ayerst International, Ortho Cilag, and Searle. None of the funders had a role in the data collection, analysis, or interpretation or in the writing of this paper.

Competing interests: The Centre of Academic Primary Care has received payments from Schering Plough and Wyeth Pharmaceutical for lectures and advisory board work provided by $\mathrm{PCH}$.

Ethical approval: The study was established before the introduction of research ethics committees in the UK. Even so, procedures were used to maintain the confidentiality of women. Correspondence between participating doctors and the study, and between the NHS central registries and the study, used a unique study number, the key to which only the general practitioners knew.

Data sharing: No additional data available.

1 Royal College of General Practitioners. Oral contraceptives and health. Pitman Medical, 1974.

2 Royal College of General Practitioners' Oral Contraception Study. Mortality among oral contraceptive users. Lancet 1977;ii:727-31.
3 Royal College of General Practitioners' Oral Contraception Study. Further analyses of mortality in oral contraceptive users. Lancet 1981;i:541-6.

4 Beral V, Hermon C, Kay C, Hannaford P, Darby S, Reeves G. Mortality associated with oral contraceptives: 25 year follow up of cohort of 46 000 women from the Royal College of General Practitioners' Oral Contraception Study. BMJ 1999;318:96-100.

5 Hannaford PC, Selvaraj S, Elliott AM, Angus V, Iversen L, Lee AJ. Cancer risk among oral contraceptive users: cohort data from the Royal College of General Practitioner's Oral Contraception Study. BMJ 2007;335:651.

6 Rosner B. Fundamentals of biostatistics. Duxbury Press, 2000.

7 Wingrave SJ, Beral V, Adelstein AM, Kay CR. Comparison of cause of death coding on death certificates with coding in the Royal College of General Practitioners' Oral Contraception Study. J Epidemiol Community Health 1981;35:51-8.

8 Owen-Smith V, Hannaford PC, Warskyj M, Ferry S, Kay CR. Effects of changes in smoking status on risk estimates for myocardial infarction among women recruited for the Royal College of General Practitioners' Oral Contraception Study in the UK. J Epidemiol Community Health 1998;52:420-4.

9 Beral V, Hermon C, Kay C, Hannaford PC, Darby S, Reeves G. Mortality in relation to method of follow-up in the Royal College of General Practitioners' Oral Contraception Study. In: Hannaford PC, Webb AMC, eds. Evidence-guided prescribing of the pill. Parthenon Publishing Group, 1996:327-39.

10 Prentice RL, Langer R, Stefanick ML, Howard BV, Hettinger M, Anderson G, et al. Combined postmenopausal hormone therapy and cardiovascular disease: toward resolving the discrepancy between observational studies and the Women's Health Initiative Clinical Trial. Am J Epidemiol 2005;162:404-14.

11 Colditz GA. Oral contraceptive use and mortality during 12 years of follow-up: the Nurses' Health Study. Ann Intern Med 1994;120:821-6.

12 Vessey M, Painter R, Yeates D. Mortality in relation to oral contraceptive use and cigarette smoking. Lancet 2003;362:185-91.

Accepted: 5 January 2010 